\title{
Influence of trees on the air temperature in outdoor spaces according to planting parameters: the case of the city of Aix-en-Provence in France
}

\author{
L. Rodriguez Potes ${ }^{1,2}$, S. Hanrot ${ }^{3}$, M. A. Dabat ${ }^{1}$ \& J. L. Izard $^{1}$ \\ ${ }^{1}$ Laboratory ABC, Architecture School of Marseille, France \\ ${ }^{2}$ French Environment and Energy Management Agency \\ (ADEME), France \\ ${ }^{3}$ Research Department, Architecture School of Marseille, France
}

\begin{abstract}
This study is part of a doctoral thesis on the thermal environment in urban green areas in a Mediterranean climate. The purpose of this paper is to demonstrate how urban spaces are subjected to the thermal influences of planting trees. It is based on the air temperature measurements in summer in several streets with trees in Aix-en Provence city in France. The results reveal the effects of trees in cooling the air temperature, according to planting parameters: the foliage percentage, the tree coverage coefficient, the planting distance and the street orientation. The conclusions show that street orientation seems to be more important on the air temperature than the foliage percentage itself, the planting distance and the tree coverage. The contribution of the foliage percentage is insignificant in east-west streets (E-W) (The difference between the street without trees and the street with tree is $0.2^{\circ} \mathrm{C}$ ) and the role of tree coverage coefficient is not certain in this orientation. The results of this study could be used to quantify thermal comfort in outdoor spaces including urban trees and their impact on energy consumption.

Keywords: urban trees, urban microclimate, air temperature.
\end{abstract}




\section{Introduction}

Urban design requires not only a theoretical knowledge of the climatic conditions and the impact of landscape elements on microclimate, but also the application of this knowledge to create microclimates that are comfortable for people and minimize the use of energy in buildings. To achieve these objectives, the trees are inevitable natural means: they can cool the hot air through evapotranspiration, provide shade on the floor and walls during the summer and control the wind speed. Similarly, cooling the air temperature through the trees is an effective way to reduce significantly the cooling energy consumptions [1]. Finally, the trees can use to filter pollutants, to act on noise reduction, like a sound barrier, to prevent soil erosion and to regenerate the air [2].

There is a growing interest from researchers and the public in topics associated with the microclimate role of urban trees and their contribution to the quality of life in cities. However, it seems that just a little part of research is taken into account in the development of design tools that integrate and organize urban vegetation in time and space.

\section{Methodology}

\subsection{Presentation of the site}

The city of this study is Aix-en-Provence, located near the Mediterranean coast in Provence, France, at latitude $43^{\circ} 31^{\prime} 52^{\prime \prime}$ north and longitude $5^{\circ} 27^{\prime} 14^{\prime \prime}$ east. The climate is characterized by exceptional sunshine of 2800 hours per year, an mean annual air temperature of $13^{\circ} \mathrm{C}$, a relative air humidity mean of $55 \%$, an aerology (mistral) attenuated by the surrounding mountains and a rainfall of $500 \mathrm{~mm}$ per year. The city center is compact; it includes contemporary buildings dating from the $17^{\text {th }}$ to the $19^{\text {th }}$ century with a commercial and residential occupancy. The choice of the city is justified by its size (itinerary of reasonable length), the presence of a wide variety of urban forms and tree alignment in a very short distance as well the presence of a weather station near the city center, which is ideal for this study.

Six streets in the city center, four with trees and two without trees, was chosen for the case study. This opens our study to a wide range of circulation spaces such as streets, avenues and boulevards. The selection of the case study is therefore based on an analysis of the green spaces in the city of Aix-en-Provence.

\subsection{Hypothesis}

The effects of trees on the thermal conditions in outdoor spaces during the summer are related to the street orientation, the planting parameters (the coverage of the crown and separations between trees and buildings) and the percentage of foliage. These three parameters are used to characterize and to analyze the results. 


\subsubsection{Hypothesis 1: orientation of the street}

Tree effects can change according to street orientation: blocking sunlight or windbreaks, etc. There are three streets orientations in our study: north-south (NS), east-west (EW) and north-east/south-west (NE-SW).

\subsubsection{Hypothesis 2: planting parameters}

The distance of planting trees in relation to buildings (tree distance) and the size of the crown (tree coverage) can change the thermal conditions. The tree coverage is the zone occupied by the crown under the street.

- $\quad$ The tree distance $D a$ to the center of the roadway is related to the width $W$ of the street and expressed by the coefficient $\mathrm{Da} / \mathrm{W}$. So, when $\mathrm{Da} / \mathrm{W}$ is closer to 1 , the trees are near the buildings, when $D a / W$ is closer to 0 , the trees are in the axis of the roadway.

- The diameter of the crown $2 d a$ is reported to $W$ and expressed by the coefficient $2 d a / W$, this is the tree coverage coefficient. So, when $2 d a / W$ is closer to 1 , the trees fill the sky, when $2 d a / W$ is 0 , there are not trees.

The intersection of these parameters gives three cases of planting trees that it we found on our study site (fig. 1).

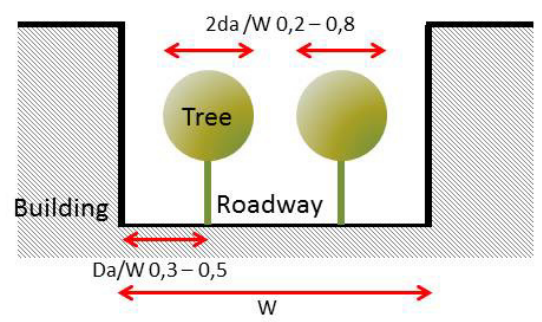

Case A

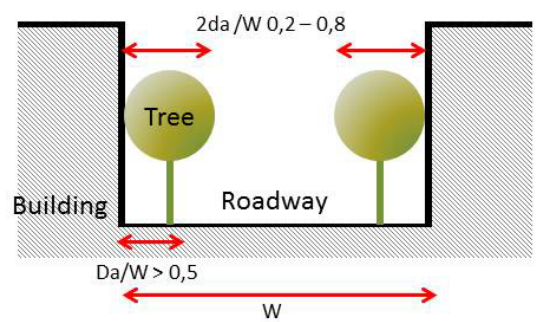

Case B

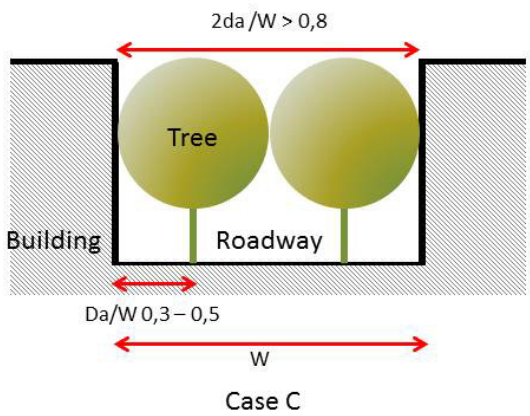

Figure 1: $\quad$ Planting parameters for every case. 
- Case A: trees separated from the building and low tree coverage coefficient: $\mathrm{Da} / \mathrm{W} 0.3$ - $0.5 ; 2 \mathrm{da} / \mathrm{W} 0.2-0.8$.

- Case B: trees near the buildings and low tree coverage coefficient: $\mathrm{Da} / \mathrm{W}>$ $0.5,2 d a / W 0.2-0.8$.

- Case C: trees near the buildings and high tree coverage coefficient: $\mathrm{Da} / \mathrm{W}$ $0.3-0.5 ; 2 d a / W>0.8$.

\subsubsection{Hypothesis 3: percentage of foliage (\% F)}

The foliage of the trees can cool the air by evapotranspiration and by the shadow on the floor and walls during the summer, reducing the radiation and control the speed of the wind. In this study, the percentage of foliage is related to the LAD (leaf area index). It indicates the total leaf area and determines the degree of light transmission and radiation. It has been calculated from the exploitation of "fish eye" pictures using the method to estimate the "Sky View Factor" (fig. 2). We define a low percentage of foliage $<45 \%$, a high percentage of foliage $>55 \%$ and a mean percentage of foliage between $45 \%$ and $55 \%$.
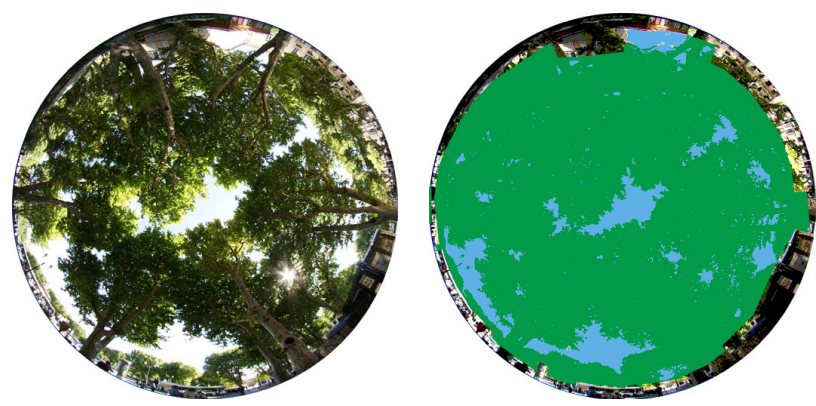

Figure 2: "Fish eye” pictures to estimate the percentage of foliage.

\subsection{Description of the experimental measurement itinerary}

For practical reasons of operability of the itinerary, we chose streets closest to each other: Victor Hugo Boulevard (NE-SW), Victor Hugo Boulevard (N-S), Cours Mirabeau (E-W), Cours Sextius (NE-SW), Giuseppe Verdi Avenue (E-W) and Joseph Villevielle Avenue (NE-SW) (fig. 3).

Measurements of air temperature, relative humidity and wind speed were made 9 September 2011. These measurements were taken every three hours (6h to 20h) at specific points in the streets, under the foliage, and a height of 1.5 meters above the ground with the multifunction device TESTO 452. A Mini Testo 175-H2 logger was placed at a reference point (R) close to the others points, $1.5 \mathrm{~m}$ above the ground in the shade to save data on the air temperature and air humidity every six minutes. The day was sunny with clear sky with a mean air temperature of $21.4^{\circ} \mathrm{C}$, a relative air humidity of $59.4 \%$, a wind speed of $0.58 \mathrm{~m} / \mathrm{s}$. The trees identified in the streets were the Platane (Platanus $X$ acerifolia) and the Micocoulier (Celtis australis). 


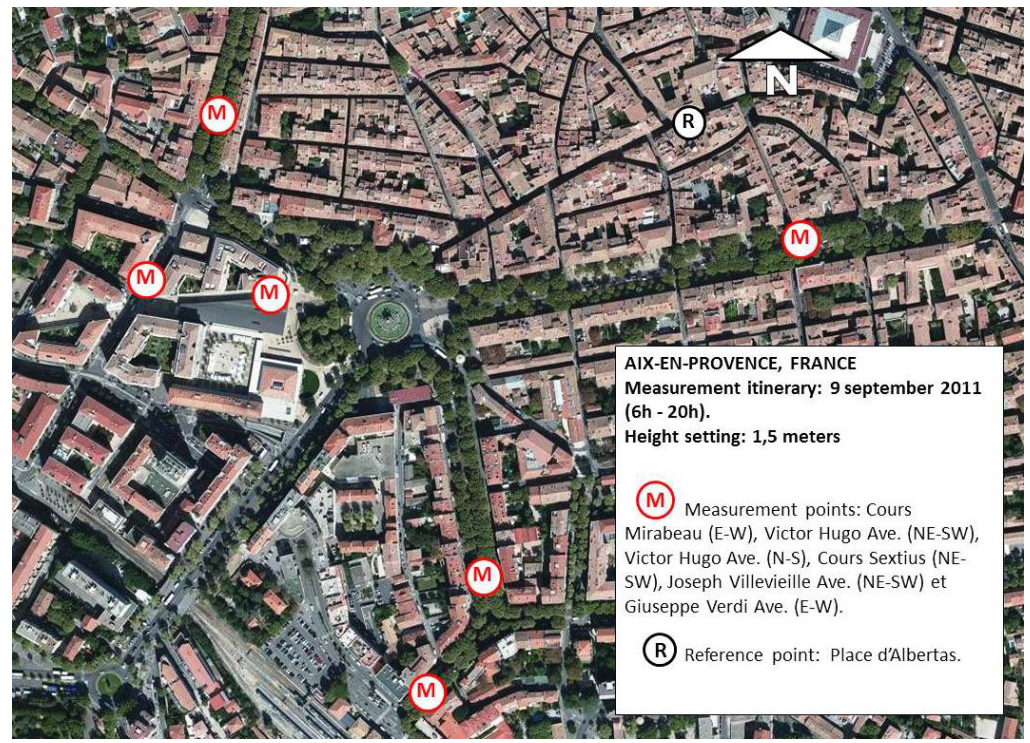

Figure 3: $\quad$ Measurement itinerary [3].

\section{Results}

The analysis of the results is based on the geometric mean air temperature $\left(\right.$ TAir $\left.^{\circ} \mathrm{C}\right)$. The table ranks the mean air temperature from the highest to the lowest and shows the parameters values (table 1).

Table 1: $\quad$ Air temperature and parameters values for every street.

\begin{tabular}{|l|c|c|c|c|c|}
\hline Street & $\begin{array}{c}\text { TAir } \\
\left({ }^{\circ} \mathrm{C}\right)\end{array}$ & Orientation & $\begin{array}{c}\text { Foliage } \\
(\% \mathrm{f})\end{array}$ & $\begin{array}{c}\text { Distance } \\
(\mathrm{Da})\end{array}$ & $\begin{array}{c}\text { Tree coverage } \\
(2 \mathrm{da})\end{array}$ \\
\hline $\begin{array}{l}\text { Victor Hugo } \\
\text { Blvd. }\end{array}$ & 25.9 & $\mathrm{~N}-\mathrm{S}$ & 53.8 & 0.4 & 0.7 \\
\hline $\begin{array}{l}\text { Cours } \\
\text { Mirabeau }\end{array}$ & 26.2 & $\mathrm{E}-\mathrm{W}$ & 43.5 & 0.4 & 0.5 \\
\hline $\begin{array}{l}\text { Giuseppe Verdi } \\
\text { Ave. }\end{array}$ & 26.4 & $\mathrm{E}-\mathrm{W}$ & 0.0 & 0.0 & 0.0 \\
\hline $\begin{array}{l}\text { Victor Hugo } \\
\text { Blvd. }\end{array}$ & 26.8 & $\mathrm{NE}-\mathrm{SW}$ & 42.5 & 0.5 & 0.9 \\
\hline Cours Sextius & 26.9 & $\mathrm{NE}-\mathrm{SW}$ & 49.7 & 0.6 & 0.8 \\
\hline $\begin{array}{l}\text { Joseph } \\
\text { Villevielle } \\
\text { Ave. }\end{array}$ & 26.9 & NE-SW & 0.0 & 0.0 & 0.0 \\
\hline
\end{tabular}


a) North-south (N-S) streets: among all streets, Victor Hugo Blvd. has the highest percentage of foliage $(53.8 \%)$, a mean tree coverage coefficient $(0.7)$ compared to others and it is the farthest of buildings (0.4). It has the lowest temperature $25.9^{\circ} \mathrm{C}$, it is the coolest of all the streets and it has the best combination of parameters.

b) East-west (E-W) streets: the Cours Mirabeau has a percentage of foliage of $43.5 \%$, a tree coverage of 0.5 and a tree distance from the building of 0.4 (farthest of buildings), even it has a light reduction of the air temperature $\left(26.2^{\circ} \mathrm{C}\right)$, two tenths below the Giuseppe Verdi Ave. $\left(26.4^{\circ} \mathrm{C}\right)$ without trees.

c) North-east/south-west (NE-SW) streets: the Cours Sextius $\left(26.9^{\circ} \mathrm{C}\right)$ is in the average in terms of foliage $49.7 \%$, a tree coverage coefficient of 0.8 and a tree distance close to buildings (0.6). The Victor Hugo Blvd. $\left(26.8^{\circ} \mathrm{C}\right)$ has a lowest percentage of foliage of $42.5 \%$, a tree coverage coefficient a little higher of 0.9 and a distance tree of 0.6. The Joseph Villevieille Ave. has an air temperature of $26.9^{\circ} \mathrm{C}$ while it has no trees $(0 \%)$ and even the Cours Sextius has an air temperature of $26.9^{\circ} \mathrm{C}$ and a percentage of foliage of $49.7 \%$ : they are the hottest NE-SW streets. The orientation and the temperature are almost constant, even the tree coverage and the foliage does not seem to influence the temperature of the air.

d) The comparison between the Victor Hugo Blvd. (N-S orientation, 53.8\% of foliage, distance 0.4 and tree coverage 0.7 ) and the Cours Mirabeau (E-W orientation, $43.5 \%$ of foliage, distance 0.4 and cover 0.5 ) shows that the Victor Hugo Blvd. has a strong tree coverage coefficient and the Cours Mirabeau has an mean value, that means, a difference of 0.2 . The distances are the same and there is a gap of foliage density of $10.3 \%$. The parameter combination in these two streets allows it to gain only $0.3^{\circ} \mathrm{C}$. The comparison between the Victor Hugo Blvd. N-S and the NE-SW streets, shows temperature differences between $0.9^{\circ} \mathrm{C}$ to $1^{\circ} \mathrm{C}$, whether trees or not. Between the E-W streets and NE-SW streets there are differences in temperature of $0.4^{\circ} \mathrm{C}$ to $0.7^{\circ} \mathrm{C}$.

\section{Discussion}

The Victor Hugo Blvd. (N-S) has all the settings for it. It has the best planting parameters and a north-south orientation. This combination gives a difference of $1^{\circ} \mathrm{C}$ compared to the highest temperature (NE-SW orientation). However, we cannot say exactly what is the weight of the orientation and the weight of these settings in the N-S orientation, if that penalizes or improves the thermal conditions. That means that we cannot say in the comparison that the lower air temperature value in the north-south street orientation is due to parameters of trees, it could be related to the orientation but it may be related to the combination of parameters planting.

Three facts arise: either the vegetation does not play a significant role in the temperature of the air, so the difference is mainly due to the orientation. Or 
improvement of the temperature is only due to the parameters of planting. Or, trees distance, combined with the orientation, reduces the air temperature. This would imply that a north-south street without trees could not have this lower temperature. However, without a north-south street in our study, a definitive conclusion is not possible.

In cases oriented east-west, the combination of parameters seems not to be very important because the street with trees and without trees have almost the same air temperature. So, this means that whatever the way we combine the planting parameters between them, there is not much impact on the temperature, in our cases the street orientation has a more strong impact. Maybe, if they have the highest values of parameters, it may have had a greater difference, for example, if we have more than $53.8 \%$ of foliage, a tree coverage of 0.9 with the minimum distance of 0.4 , we may have lower air temperatures.

In the NE-SW street, it is difficult to estimate the weight of each parameter in the air temperature value. The combination of all these factors gives almost the same air temperature value, therefore, the combination of distance, percentage of foliage and tree coverage, do not seem to be effective when the street is oriented NE-SW. For example, the three NE-SW streets have a percentage of foliage from $0 \%$ to $49.7 \%$, this is a very substantial difference, but it seems that it does not play a positive role.

It is also observed by comparing all the cases that have a mean percentage of foliage with a high tree coverage coefficient, this is equal to a compensation or balance between both. But the optimization of these parameters is reduced by the proximity to the buildings. However, if the planting distance from the buildings is reduced and at the same time it is combined with a good tree coverage and a relatively low percentage of foliage, there is a balance or compensation. That means that the proximity of trees to the buildings may be a factor penalizing.

A higher planting distance from the buildings, as well as a greater tree coverage, whether or not combined, has a positive effect because the air temperature is lower even if the percentage of foliage is lower. But when the trees are very close to the buildings and the tree cover is smaller, that becomes a negative factor, because the air temperature rises even if there are a high percentage of foliage. But we do not know what is the weight in improving the temperature of these factors. It is still unclear, but it may still award that the distance plays an important role in the air temperature. The street orientation seems to be more important than the vegetation itself, but nevertheless, some parameters are having some effect on the temperature of the air, such as the distance from the buildings and the tree coverage coefficient.

\section{Conclusion}

The analysis of the parameters related to trees and urban planning showed relationships between the way the trees are planted in the city and the thermal condition of these spaces. The orientation, the distances from the buildings and the tree coverage have influences on the air temperature.

Based on the analysis results, we can emphasize these facts: 
1. The parameters of the vegetation do not play an important role in the air temperature of the NE-SW street.

2. The tree planting combined with N-S orientation allows a low air temperature, which itself could not have had this performance.

3. Depending on the street orientation, the percentage of foliage may be more or less effective.

4. The proximity of the tree to the buildings plays an important role: A high distance of the trees from the building reduces the air temperature. A low distance of the trees form the building increases the air temperature.

5 . The streets orientation, the tree distance and the tree coverage combined or not can compensate a low percentage of foliage and improve a thermal performance.

6. In terms of orientation, E-W streets have better thermal performance than NESW. An E-W street, even without trees, is more favorable than a NE-SW street with trees.

7. If the vegetation improves thermal conditions, the street orientation improves too and the combination of both improves greatly.

It is not only the trees that contribute to changing the thermal conditions, but also the urban forms, including street orientation. This is why we get better results if a true compromise occurs between the form of construction of our cities and the environment

\section{References}

[1] Akbari et al. Peak power and cooling energy savings of shade trees. Akbari, H., Kurn, D.M., Bretz, S.E., Hanford, J.W, Energy and Buildings, 25, 139-148, 1997.

[2] Panagopoulos. Using microclimatic landscape design to create thermal comfort and energy efficiency, Actas da $1^{\text {a }}$ Conferência sobre Edifícios Eficientes, Universidade do Algarve, 25 de Janeiro, 2008.

[3] Aix-en-Provence map taken $11^{\text {th }}$ February 2012 from http://www.bing.com /maps/?FORM=Z9LH3. 